\title{
Co-induction of labour analgesia: epidural test dose and low dose spinal
}

\author{
Author: Towfique M Islam FFARCSI, E Lew MMED \\ Affiliation: Department of Anaesthesia, KK Women's \& Children's Hospital, Singapore.
}

Introduction: Immediate epidural test dose in combined spinal-epidural is not practised routinely. Volume effect of effect of epidural top-up is well known. The purpose of this study was to investigate if an epidural test dose will complement the CSE to provide a safe and effective labour analgesia.

Method: After ethics approval and informed consent, 50 healthy women with singleton pregnancy at $3-5 \mathrm{~cm}$ of cervical dilatation requesting epidural analgesia were recruited into this prospective, randomised, double blind, placebo-controlled trial. 10mls of normal saline (NS) or $0.1 \%$ bupivacaine (B), epidural top-up was given 5 minutes after the intrathecal injection of $1 \mathrm{mg}$ of bupivacaine with $5 \mathrm{~g}$ of fentanyl, followed by infusion of $0.1 \%$ bupivacaine with $2 \mathrm{~g}$ of fentanyl at $10 \mathrm{mls} / \mathrm{hr}$ was started. Pain was assessed using verbal analogue scale (VAS=0-100) score and effective pain relief was defined as a VAS $<20$ after 10min. Pain score, sensory blockade, motor blockade, maternal and foetal vital signs were recorded. To detect a difference of $34 \%(\mathrm{NS}=35 \% \mathrm{vsB}=1 \%)$ in the incidence of VAS>20 at 10mins, 25 women were required in each group with a power of $90 \%$ and a two-sided test of 5\%. Categorical and continuous data were analysed using Fisher's exact, Chi-square and Mann Whitney-U test.

Results: The groups were similar in demographic and obstetric data. B group had higher effective pain relief compared to saline group (Relative Risk $=2.08,95 \%$ CI 1.38 to 3,38, $\mathrm{p}<0.001)$. Sensory block at 10mins was higher in B (T7 vs T11; $\mathrm{p}<0.001)$ but at safe level. There was no incidence of foetal heart rate deceleration, maternal hypotension ( $>0.05$, repeated ANOVA) or motor blockade after test dose. The median duration of analgesia was significantly prolonged in B (670 vs 90mins; $p<0.001)$. B had less breakthrough pain $12 \%$ vs $69.23 \%$ (Odds ratio $=16.39, \mathrm{p}<0.001$ ).

Conclusion: $10 \mathrm{mls}$ of $0.1 \%$ bupivacaine can be used as an epidural test dose immediately after the intrathecal injection of $1 \mathrm{mg}$ bupivacaine with $5 \mathrm{~g}$ of fentanyl in $2 \mathrm{ml}$, to provide safe effective analgesia with a lower incidence of breakthrough pain in early labour. It does enhance the analgesic effect of very low dose spinal. 